\title{
Sodium Butyrate Protects N2a Cells against A $\beta$ Toxicity In Vitro
}

\author{
Jingxuan Sun $\mathbb{D},{ }^{1}$ Boyu Yuan $\mathbb{D},{ }^{1,2}$ Yancheng $W u\left(\mathbb{D},{ }^{1}\right.$ Yuhong Gong $\mathbb{D},{ }^{1}$ Wenjin Guo $\mathbb{D},{ }^{1}$ \\ Shoupeng Fu $\mathbb{D}^{1},{ }^{1}$ Yongxin Luan $\mathbb{D}^{3}{ }^{3}$ and Wei Wang $\mathbb{D}^{1,4}$ \\ ${ }^{1}$ Key Laboratory of Zoonosis Research, Ministry of Education, College of Veterinary Medicine, Jilin University, \\ Changchun 130062, China \\ ${ }^{2}$ Department of Pharmacology, College of Basic Medical Science, Jilin University, Changchun 130012, China \\ ${ }^{3}$ First Clinical Hospital of Jilin University, Changchun, China \\ ${ }^{4}$ Innovative Institute of Animal Healthy Breeding, Key Laboratory of Waterfowl Healthy Breeding of Guangdong Province, College of \\ Animal Sciences and Technology, Zhongkai University of Agriculture and Engineering, Guangzhou, China
}

Correspondence should be addressed to Yongxin Luan; yongxinluan@163.com and Wei Wang; wang_wei99@jlu.edu.cn

Received 16 February 2020; Revised 1 April 2020; Accepted 3 April 2020; Published 15 April 2020

Academic Editor: Eduardo Dalmarco

Copyright ( 2020 Jingxuan Sun et al. This is an open access article distributed under the Creative Commons Attribution License, which permits unrestricted use, distribution, and reproduction in any medium, provided the original work is properly cited.

\begin{abstract}
Alzheimer's disease $(\mathrm{AD})$ is a common neurodegenerative disease. $\mathrm{A} \beta$ plays an important role in the pathogenesis of $\mathrm{AD}$. Sodium butyrate $(\mathrm{NaB})$ is a short-chain fatty acid salt that exerts neuroprotective effects such as anti-inflammatory, antioxidant, antiapoptotic, and cognitive improvement in central nervous system diseases. The aim of this study is to research the protective effects of $\mathrm{NaB}$ on neurons against $\mathrm{A} \beta$ toxicity and to uncover the underlying mechanisms. The results showed that $2 \mathrm{mM} \mathrm{NaB}$ had a significant improvement effect on $\mathrm{A} \beta$-induced N2a cell injury, by increasing cell viability and reducing ROS to reduce injury. In addition, by acting on the GPR109A receptor, $\mathrm{NaB}$ regulates the expression of AD-related genes such as APP, NEP, and BDNF. Therefore, $\mathrm{NaB}$ protects $\mathrm{N} 2 \mathrm{a}$ cells from $\mathrm{A} \beta$-induced cell damage through activating GPR109A, which provides an innovative idea for the treatment of $\mathrm{AD}$
\end{abstract}

\section{Introduction}

Alzheimer's disease (AD) belongs to neurodegenerative diseases, which is characterized by extracellular amyloid deposition and intracellular neurofibrillary tangles [1-3]. Clinically, it shows through generalized dementia such as memory impairment, aphasia, disuse, loss of recognition, impairment of visuospatial skills, executive dysfunction, and personality or behavioral changes. Although there is still controversy about the pathogenesis of $\mathrm{AD}$, the more accepted hypothesis is that the abnormal decomposition or production of the amyloid precursor protein (APP) leads to the deposition of neurotoxic $\beta$-amyloid $(A \beta)$ oligomers, triggering an amyloid cascade reaction which finally leads to neurodegeneration [4-7]. Undisputed evidence says there are insoluble amyloid plaques formed by $\mathrm{A} \beta$ deposition in the brain of $\mathrm{AD}$ patients [8]. Although significant progress has been made in the study of its pathogen- esis, the current clinical treatment methods can only delay the development of $\mathrm{AD}$ and cannot reverse the existing neuron damage. Therefore, it is the primary task to find effective therapeutic targets and therapeutic drugs effectively, to prevent damage to the nervous system, and to repair damaged nerve cells under the toxicity of $\mathrm{A} \beta$ plaques, thereby improving cognitive ability in early $\mathrm{AD}$ patients.

Butyrate is under a wide range of biological functions. Studies have shown that butyrate plays an active role in brain disorders in a variety of neurodegenerative diseases such as Alzheimer's disease, Parkinson's disease, and Huntington's disease [9-12]. Sodium butyrate $(\mathrm{NaB})$ is a common form of butyrate. A study by Sun et al. showed that $\mathrm{NaB}$ protects brain against amphetamine-induced oxidative stress in rats [13]. Some studies indicate that the $A \beta$-mediated oxidative stress is a major factor in the pathology of $\mathrm{AD}[14,15]$. In an $\mathrm{AD}$ mouse model, $\mathrm{NaB}$ significantly improves the associative memory of APPPS1-21 mice (Alzheimer's mice) [16]. 
TABle 1: Primers for real-time PCR.

\begin{tabular}{|c|c|c|}
\hline Gene & Sequences & Length (bp) \\
\hline \multirow{2}{*}{ GPR109A } & Forward: 5' -CCGTCGTGTAGTCTGTCTCGTG-3' & \multirow[b]{2}{*}{119} \\
\hline & Reverse: 5'-GCTGCGGTTATTGTTGGACT-3' & \\
\hline \multirow{2}{*}{ APP } & Forward: 5' -CCAAGGAGGGCATCTTGCAG-3' & \multirow{2}{*}{138} \\
\hline & Reverse: 5'-TGTGGGTGTGTGTCTTGCAC-3’' & \\
\hline \multirow{2}{*}{ BDNF } & Forward: 5' -CGACGACATCACTGGCTGAC-3' & \multirow{2}{*}{124} \\
\hline & Reverse: 5' -AGCATCACCCGGGAAGTGTA-3' & \\
\hline \multirow{2}{*}{ NEP } & Forward: $5^{\prime}$-CTA CCG GCC AGA GTA TGC AG-3' & \multirow{2}{*}{133} \\
\hline & Reverse: $5^{\prime}$-TTG CGG CAA TGA AAG GCA TC-3' & \\
\hline \multirow{2}{*}{ GAPDH } & Forward: 5'-GCCATCACTGCCACCCAGAA-3' & \multirow{2}{*}{153} \\
\hline & Reverse: $5^{\prime}$-GCCAGTGAGCTTCCCGTTGA-3' & \\
\hline
\end{tabular}

G protein-coupled receptors are widely found in mammals and are encoded by approximately 800 genes. Typical natural ligands for $G$ protein-coupled receptors include hormones, mediators, neurotransmitters, polypeptides, amino acids, and ions. Studies have demonstrated that in the process of energy metabolism, certain nutrients or their metabolites, which are the basic raw materials, activate $G$ protein-coupled receptors to regulate metabolism [17]. The GPR109A receptor, otherwise known as niacin receptor 1 , belongs to the $G$ protein-coupled receptor family. Niacin is the major ligand for GPR109A, but the physiological concentration of niacin does not reach the threshold required to activate the receptor [18], while butyrate, as a suitable candidate ligand, has the potential in binding the GPR109A receptor at a low concentration [19]. As a Gi/G0-coupled receptor, pertussis toxin (PTX) blocks the effects of GPR109A.

Therefore, this study was aimed at investigating the protective effect of $\mathrm{NaB}$ on $\mathrm{N} 2 \mathrm{a}$ cells induced by $\mathrm{A} \beta$ in vitro and at exploring the mechanisms on how GPR109A is involved.

\section{Materials and Methods}

2.1. Cell Culture. Mouse neuroblastoma N2a cells were donated by the pathology laboratory of the College of Veterinary Medicine, Jilin University. All cells were cultured in DMEM medium (Gibco, Grand Island, NY 14072, USA) containing $10 \%$ fetal bovine serum (FBS) (Clark Bioscience, USA) at $37^{\circ} \mathrm{C}$ in a humidified incubator with $5 \% \mathrm{CO}_{2} . \mathrm{N} 2 \mathrm{a}$ cells were cultured in a $60 \mathrm{~mm} \times 15 \mathrm{~mm}$ cell culture dish (Life Science, Oneonta, USA).

2.2. Treatment of N2a Cells. A $\beta_{25-35}$ (synthesized by Shanghai Sangon Biological Engineering Technology \& Services Co.) was diluted in distilled water at a concentration of $16 \mathrm{mmol} / \mathrm{L}$ and was maintained at $37^{\circ} \mathrm{C}$ for 7 days to preage the peptide. N2a cells were divided into four groups: the control (NT) group, the $\mathrm{NaB}(2 \mathrm{mM})$ group, the $\mathrm{A} \beta_{25-35}(40 \mu \mathrm{mol} / \mathrm{L})$ treatment group, and the $\mathrm{A} \beta_{25-35}(40 \mu \mathrm{mol} / \mathrm{L})$ with $\mathrm{NaB}(2 \mathrm{mM})$ pretreatment group. Cells were starved for $4 \mathrm{~h}$ and then pretreated with $2 \mathrm{mM} \mathrm{NaB}$ for $2 \mathrm{~h}$ before $\mathrm{A} \beta_{25-35}$ was added. RNA or protein from N2a cells was extracted after $24 \mathrm{~h}$. Each experiment was repeated three times.

2.3. Cell Counting Kit-8 Assay. N2a cells were centrifuged and seeded in 96-well plates at a density of $2 \times 10^{4}$ cells/ mL. $200 \mu \mathrm{L}$ of PBS was added, and the cells were incubated at $37^{\circ} \mathrm{C}$. After 24 hours, the complete medium was removed, and $200 \mu \mathrm{L}$ prewarmed DMEM basal medium was added for cell starvation. Subsequently, $\mathrm{NaB}$ was added after $4 \mathrm{~h}$ to pretreat the cells, and after $2 \mathrm{~h}, \mathrm{~A} \beta_{25}$ 35 was added for stimulation. There were 5 replicates for each test group. After $24 \mathrm{~h}$ of treatment, $10 \mu \mathrm{L}$ CCK8 (Saint-Bio, Shanghai, China) was added to each well. After $1 \mathrm{~h}$, absorbance (OD) was measured at $450 \mathrm{~nm}$ in a microplate reader.

2.4. Reactive Oxygen Species Assay Kit. N2a cells were seeded in a 96-well plate at a liquid volume of $2 \times 10^{4}$ cells/mL, and each treatment group was set to five repeats. After culturing for $24 \mathrm{~h}$, replace with DMEM incomplete medium to starve the cells for $4 \mathrm{~h}$. Then, $2 \mathrm{mM} \mathrm{NaB}$ was added for preprotection for $2 \mathrm{~h}$. And the cells were stimulated with $\mathrm{A} \beta_{25-35}$ at a dose of $40 \mu \mathrm{M} /$ well for $24 \mathrm{~h}$. Thereafter, DCFH-DA was diluted with noncomplete medium at a ratio of $1: 2000$ and cultured for $40 \mathrm{~min}$. The detection wavelength is $488 \mathrm{~nm}$ excitation wavelength and $525 \mathrm{~nm}$ emission wavelength.

2.5. Real-Time $q P C R$. RNA extraction, reverse transcription, and RT-PCR were performed following our previously published procedure [20]. The primer sequences are shown in Table 1.

2.6. Western Blot. Total proteins were extracted from N2a cells following the procedure we described previously [20]. Subsequently, western blotting was performed according to the standard protocol [20]. Antibody information is as follows: specific antibodies including tubulin (1:4000), APP 


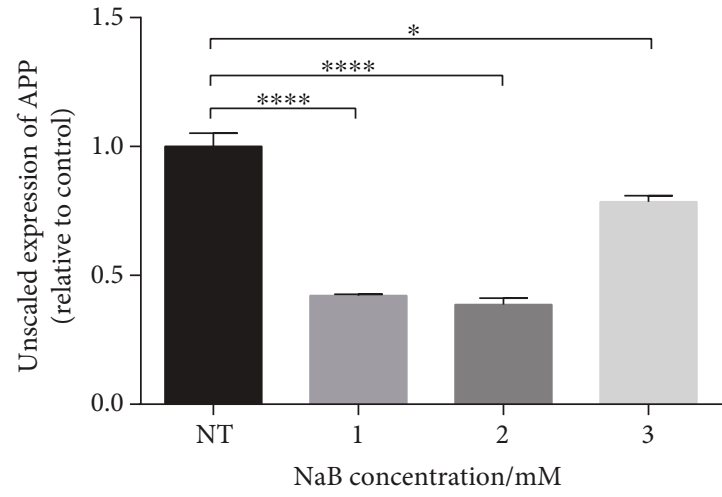

(a)

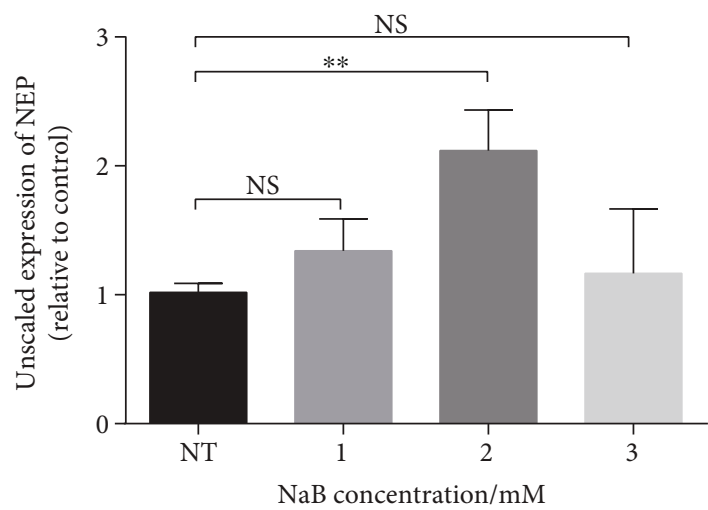

(c)

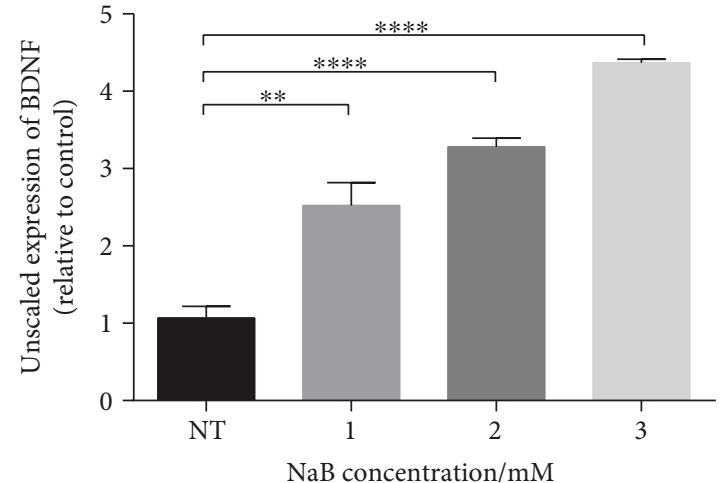

(b)

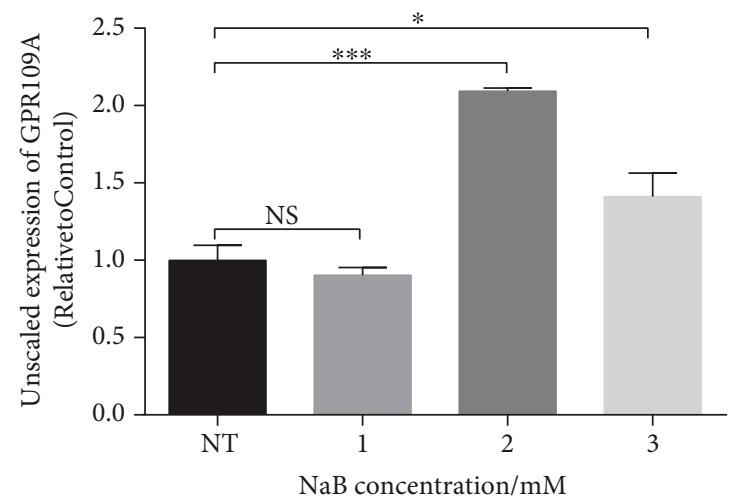

(d)

FIgURE 1: $\mathrm{NaB}$ regulates a variety of AD-related genes in N2a cells. N2a cells were treated with $0,1,2$, and $3 \mathrm{mM} \mathrm{NaB}$ for 24 hours. (a-d) The mRNA expressions of APP, BENF, NEP, and GPR109A were assessed by RT-PCR $\left(n=3\right.$, means \pm SD, Student's $t$-test, ${ }^{*} P<0.05,{ }^{* *} P<0.01$, ${ }^{* * *} P<0.001$, and ${ }^{* * * *} P<0.0001$ ). The effect of $\mathrm{NaB}$ on $\mathrm{N} 2$ a cells is most obvious when the concentration is $2 \mathrm{mM}$.

(1:5000; A8717, Sigma-Aldrich), NEP (1:1500; 18008-1-AP, Proteintech), BDNF (1:1000; 28205-1-AP, Proteintech), GPR109A (1:500; NBP1-92180,NOVUS), goat anti-rabbit IgG-HRP (1:3000; Santa Cruz Biotechnology), and goat anti-mouse IgG-HRP antibody (1:3000; Santa Cruz Biotechnology).

2.7. Statistical Analysis. The results are expressed as the mean \pm SD (or mean \pm SEM). Statistical analysis was performed using Student's $t$-test or one-way ANOVA followed by Tukey's post hoc test using Prism5.0 (GraphPad Software). $P$ values $<0.05$ were considered as statistically significant.

\section{Result}

3.1. NaB Regulates a Variety of AD-Related Genes in N2a Cells. According to our previous results, we found that $\mathrm{NaB}$ has effects on multiple cells in regulating gene expression. In order to examine the effect of $\mathrm{NaB}$ on $\mathrm{N} 2 \mathrm{a}$ cells and obtain the optimal concentration, we detected $\mathrm{AD}$-related genes in $\mathrm{N} 2 \mathrm{a}$ cells by RT-PCR, under the treatment of 1,2 , and $3 \mathrm{mM} \mathrm{NaB}$. Compared with the control group, $2 \mathrm{mM}$ $\mathrm{NaB}$ had the most significant inhibitory effect on APP (Figure 1(a)) and the promotion effect on NEP and BDNF
(Figures 1(b) and 1(c)). In the subsequent experiments, we chose $2 \mathrm{mM}$ as the appropriate concentration of $\mathrm{NaB}$. In addition, we found that $\mathrm{NaB}$ also significantly increases the expression of GPR109A (Figure 1(d)).

3.2. NaB Shows Protective Effect on A $\beta$-Induced N2a Cell Viability Decrease. A $\beta$ oligomer is cytotoxic and can significantly reduce cell vitality. When the concentration of $\mathrm{A} \beta$ reached $40 \mu \mathrm{M}, \mathrm{A} \beta$ caused a significant decrease in cell viability (Figure 2(a)). To investigate the protective effect of $\mathrm{NaB}$ on $\mathrm{N} 2 \mathrm{a}$ cells, we used CCK- 8 to detect cell viability under $\mathrm{A} \beta$ oligomer incubation. The results show that compared with the control group, $\mathrm{A} \beta$ dramatically decreased cell viability, while $\mathrm{NaB}$ had no significant effect on cell viability (Figure 2(b)). Compared with $\mathrm{A} \beta$ treatment, $\mathrm{NaB}$ protected $\mathrm{N} 2 \mathrm{a}$ cells on cell viability significantly under $\mathrm{A} \beta$ oligomer incubation (Figure 2(b)).

3.3. NaB Attenuates $A \beta$ Toxicity and Maintains Mitochondrial Respiratory Function in N2a Cells. ROS are mainly produced in the mitochondrial electron-transport chain. The accumulation of ROS reflects the damage degree of mitochondrial function. Using a ROS assay kit, we found that $\mathrm{A} \beta$ made $\mathrm{N} 2 \mathrm{a}$ cells produce a large amount of ROS 


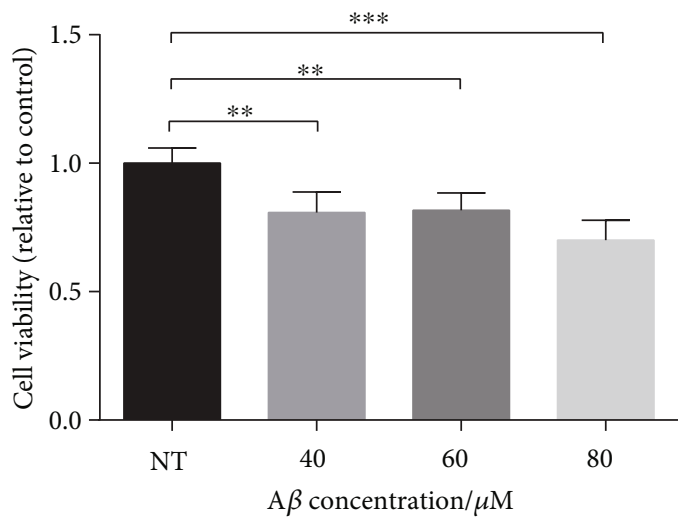

(a)

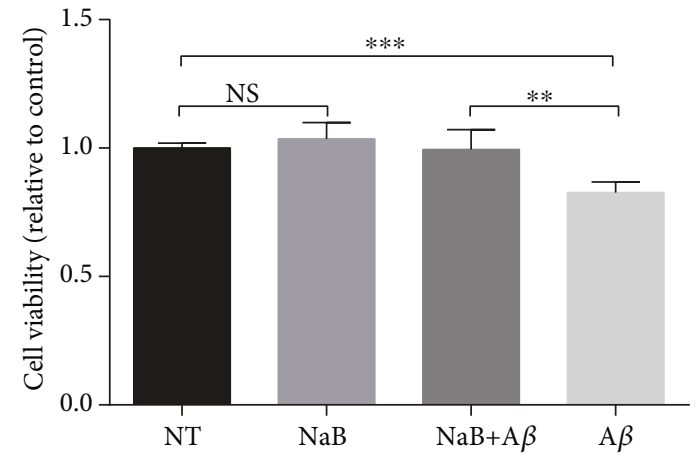

(b)

Figure 2: $\mathrm{NaB}$ shows protective effect on $\mathrm{A} \beta$-induced N2a cell viability decrease. (a) Effect of $\mathrm{A} \beta_{25-35}$ on N2a cell viability. Cells were incubated with $0,40,60$, or $80 \mu \mathrm{M} \mathrm{A} \beta_{25-35}$ for 24 hours $\left(n=4\right.$, means \pm SD, Student's $t$-test, ${ }^{* *} P<0.01$, and $\left.{ }^{* * *} P<0.001\right)$. (b) Effect of $2 \mathrm{mM} \mathrm{NaB}$ pretreatment on cell viability challenged by $40 \mu \mathrm{M} \mathrm{A} \beta_{25-35}$ for 24 hours. Cells were starved for $4 \mathrm{~h}$ and then pretreated with $2 \mathrm{mM} \mathrm{NaB}$ for $2 \mathrm{~h}$ before $\mathrm{A} \beta_{25-35}$ was added. Cell viability was analyzed by the CCK- 8 assay $(n=4$, means \pm SD, Student's $t$-test, ${ }^{* *} P<0.01$, and $\left.{ }^{* * *} P<0.001\right)$. When the concentration of $\mathrm{A} \beta$ is $40 \mu \mathrm{M}$, it had caused obvious damage to the $\mathrm{N} 2 \mathrm{a}$ cells. After pretreatment with $2 \mathrm{mM} \mathrm{NaB}$, cell viability was restored.

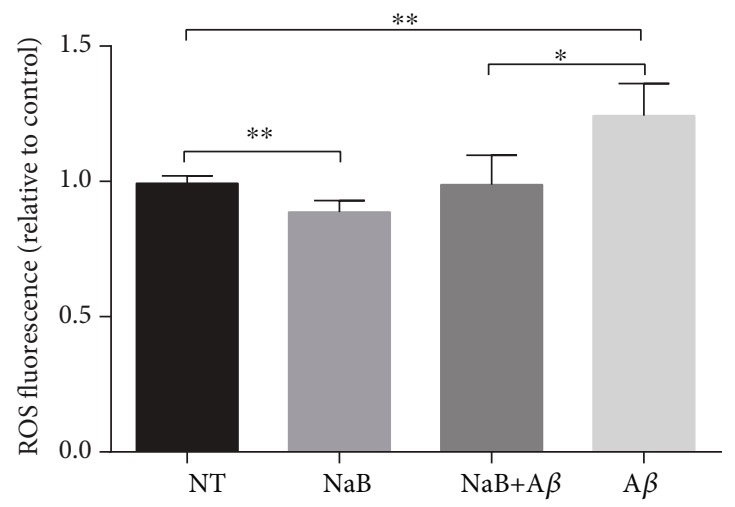

Figure 3: $\mathrm{NaB}$ attenuates $\mathrm{A} \beta$ toxicity and maintains mitochondrial respiratory function in $\mathrm{N} 2 \mathrm{a}$ cells. Effect of $2 \mathrm{mM} \mathrm{NaB}$ pretreatment on ROS challenged by $40 \mu \mathrm{M} \mathrm{A} \beta_{25-35}$ for 24 hours. Cells were starved for $4 \mathrm{~h}$ and then pretreated with $2 \mathrm{mM} \mathrm{NaB}$ for $2 \mathrm{~h}$ before $\mathrm{A} \beta_{25-35}$ was added. The ROS was assessed by a ROS assay kit $\left(n=4\right.$, means $\pm \mathrm{SD}$, Student's $t$-test, ${ }^{*} P<0.05$, and $\left.{ }^{* *} P<0.01\right)$. When the concentration of $\mathrm{A} \beta$ is $40 \mu \mathrm{M}$, it had led to increased ROS in N2a cells. After pretreatment with $2 \mathrm{mM} \mathrm{NaB}$, ROS was reduced to normal levels.

(Figure 3), while treating with $\mathrm{NaB}$ significantly inhibited the production of $\mathrm{A} \beta$-induced ROS in N2a cells (Figure 3).

\subsection{NaB Suppresses APP Expression and Increases} BDNF/NEP Level in GPR109A-Dependent Manner. We have proven that $\mathrm{NaB}$ has a positive effect on $\mathrm{A} \beta$-induced neurocyte injury. To investigate whether this effect is mediated by GPR109A, we treated N2a cells with PTX, which inhibits the $G$ protein and its physiological function in the signaling pathway. We found both in the mRNA level (Figure 4) and in the protein level (Figure 5), compared with the NaB group; after PTX treatment, the inhibitory effect of $\mathrm{NaB}$ on APP and the promoting effect on NEP and BDNF were alleviated. Meanwhile, NaB significantly increased GPR109A gene expression. These results indicate that the GPR109A is necessary for mediating $\mathrm{AD}$-related gene expression regulated by $\mathrm{NaB}$.

\section{Discussion}

Butyrate reportedly exerts numerous beneficial effects on the gut, immune system, central nervous system, and cardiovascular system [21]. Previous studies have shown that butyrate has a positive effect on both astrocytes [22] and microglia [23-26] of the central nervous system. Moreover, previous research in our laboratory shows that $\beta$-hydroxybutyric acid as a short-chain fatty acid, the same with butyrate, protected dopaminergic neurons through inhibiting microglia-mediated neuroinflammation both in vitro and in vivo [27] and limited the excessive activation of microglia and inhibited the production of inflammatory cytokines 


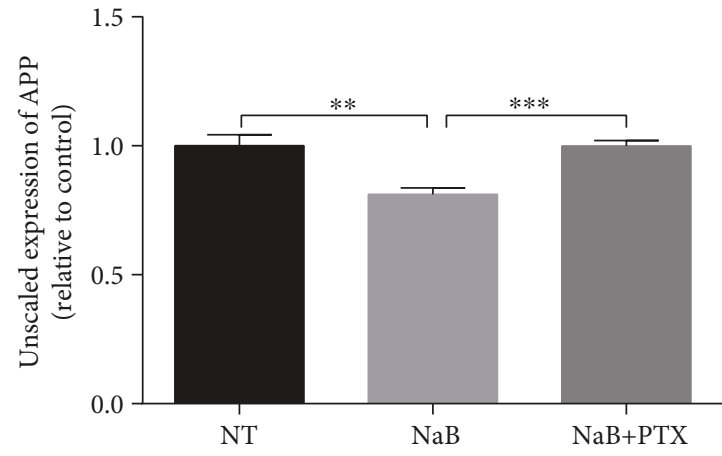

(a)

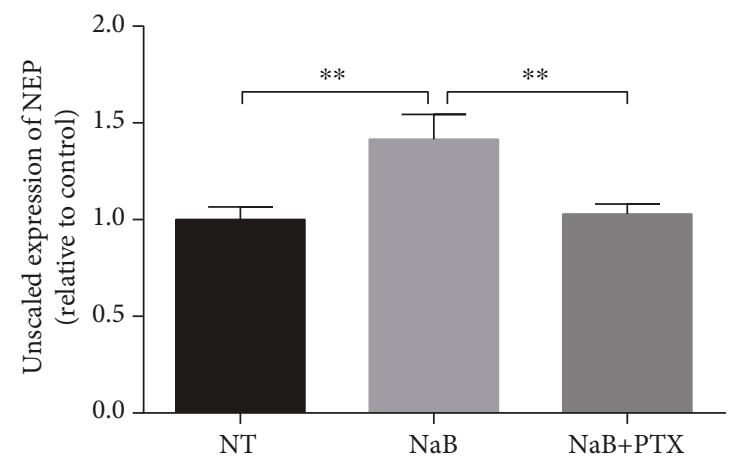

(c)

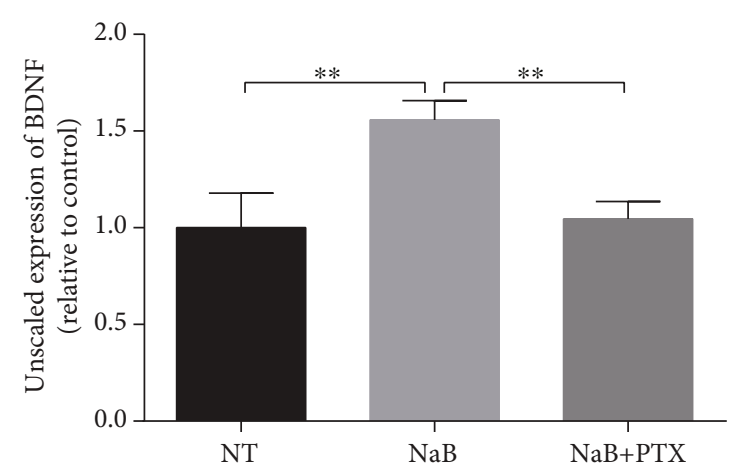

(b)

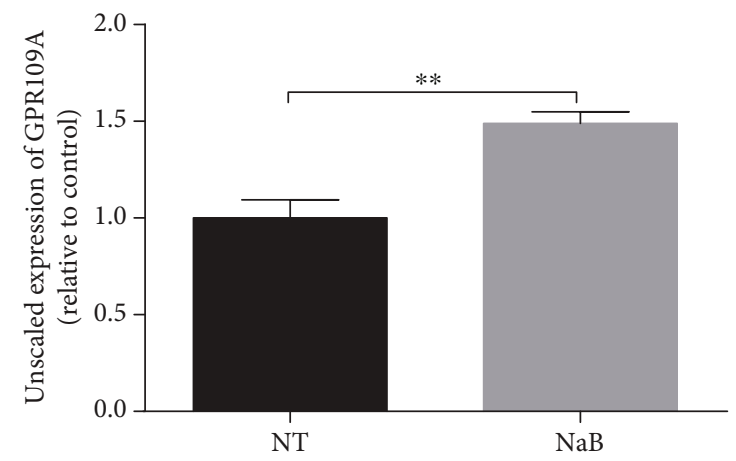

(d)

FIGURE 4: NaB suppresses APP expression and increases the BDNF/NEP level in a GPR109A-dependent manner in the mRNA level. The mRNA expressions of APP, BENF, NEP, and GPR109A were assessed by RT-PCR. The N2a cells were pretreated for 1 hour with $1 \mathrm{mM}$ PTX and then incubated for 24 hours with $2 \mathrm{mM} \mathrm{NaB}$. (a-d) PTX inhibited NaB-mediated change in APP, BDNF, NEP, and GPR109A mRNA expression $\left(n=3\right.$, means $\pm \mathrm{SD}$, Student's $t$-test, ${ }^{*} P<0.05,{ }^{* *} P<0.01$, and $\left.{ }^{* * *} P<0.001\right) .2$ mM NaB reduced transcription of APP and increased transcription of BDNF and NEP. At the same time, NaB promoted the transcription of the GPR109A.

in 5XFAD mice [28]. However, the effects and mechanism of butyrate on neuronal cell regulation, especially under $\mathrm{AD}$ conditions and $\mathrm{A} \beta$ toxicity, need to be studied well and clarified. Our results suggest that $\mathrm{NaB}$ reduces $\mathrm{A} \beta$ induced $\mathrm{N} 2 \mathrm{a}$ cell damage by reducing ROS. $\mathrm{NaB}$ inhibits the expression of APP, promotes the expression of NEP and BDNF in N2a cells by activating G proteins, especially GPR109A. These results suggest that $\mathrm{NaB}$ may be a candidate for the cure of AD.

$\mathrm{A} \beta$ is produced by the cleavage of APP by $\beta$ - and $\gamma$-secretase [29]. Previous studies have found that the overexpression of APP led to the increase of $\mathrm{A} \beta$, which is closely related to the occurrence of $\mathrm{AD}$ [30-43]. It has been shown that BHBA can improve cognitive behavior in an Alzheimer's disease mouse model. In the course of its action, the expression of APP decreased [28]. On the one hand, NEP can effectively disintegrate $A \beta$ and slow down the development of amyloidosis [44-46]. Therefore, the dysregulation of NEP activity can promote the deposition of $\mathrm{A} \beta$ and affect the development of AD [47-49]. According to the research of Wei et al., it is shown that pratensein can promote the expression of NEP and reduce the deposition of $\mathrm{A} \beta$ [50]. In addition, early studies have shown that during the occurrence and development of $\mathrm{AD}$, the expression of $\mathrm{BDNF}$ is reduced both in mRNA and protein levels [51-53]. Increased
BDNF in the blood slowed AD development and cognitive decline [51, 53-55]. Studies have shown that the expression of BDNF is significantly reduced in an $\mathrm{A} \beta_{1-42}$-induced rat model, while pratensein can reverse the decrease of BDNF expression [50]. In our study, $\mathrm{NaB}$ can reduce the production of APP in mRNA and protein levels, thereby reducing the formation of $\mathrm{A} \beta$. Simultaneously, $\mathrm{NaB}$ can also promote the generation of NEP, sequentially promoting the degradation of $\mathrm{A} \beta$. In addition, $\mathrm{NaB}$ can also promote the production of $\mathrm{BDNF}$ and reduce $\mathrm{A} \beta$-induced cell damage.

It has been proved that the deposition of $\mathrm{A} \beta$ in mitochondria and the promotion of ROS under the action of various metal ions are important features of $\mathrm{AD}$ during the development of AD [56-58]. The analysis of mouse models and autopsy of $\mathrm{AD}$ patients showed that mitochondrial dysfunction led to increased ROS, further exacerbating mitochondrial dysfunction, which further resulted in the deposition of $\mathrm{A} \beta$. In $\mathrm{AD}$ pathology, with the accumulation of ROS, $\mathrm{A} \beta$ deposition caused mitochondrial dysfunction, which can lead to neuronal cell death [59]. Our study shows that $\mathrm{NaB}$ can reduce the production of ROS, thereby maintaining mitochondrial function and reducing $\mathrm{A} \beta$-induced cell damage.

We showed the strong evidence that $\mathrm{NaB}$ inhibits the expression of APP, promotes the expression of NEP and 

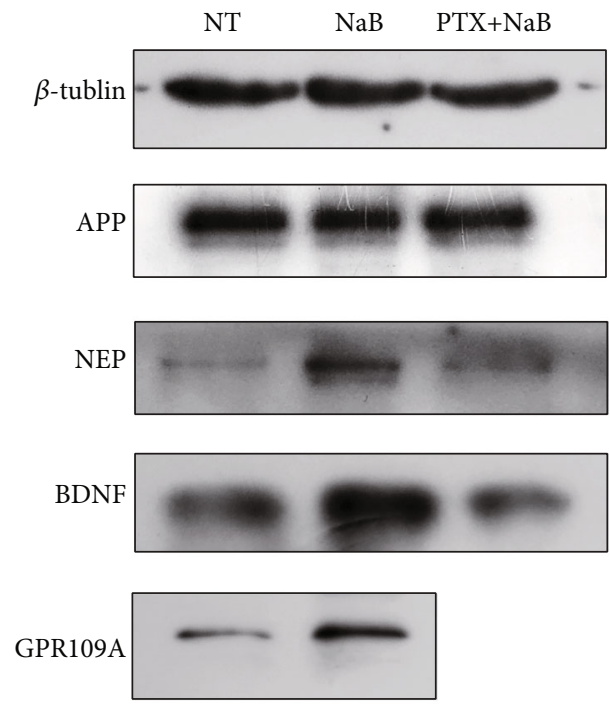

(a)

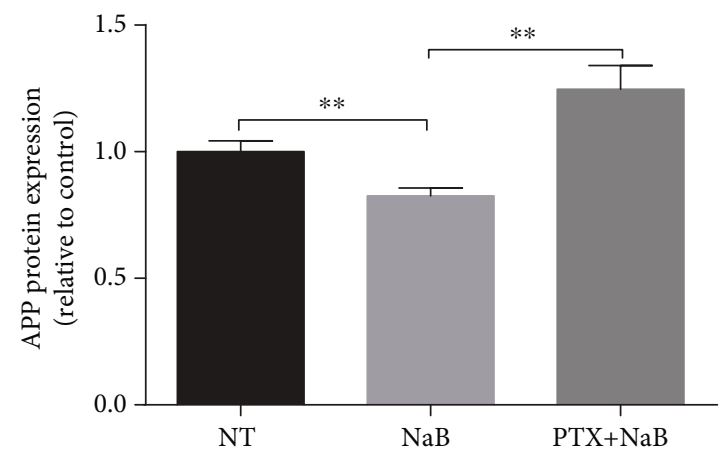

(b)
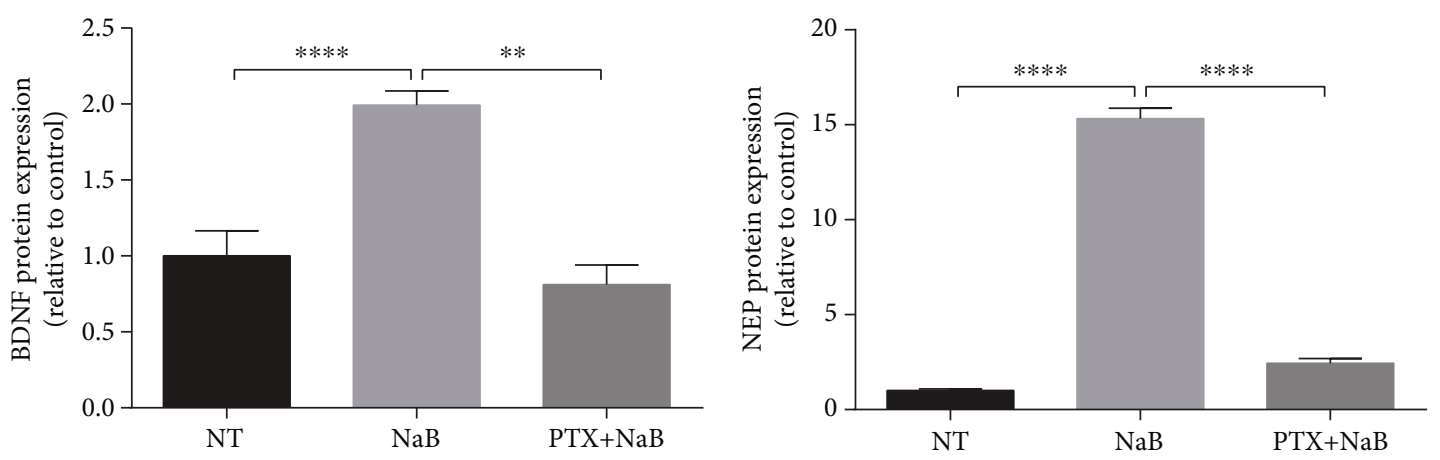

(c)

(d)

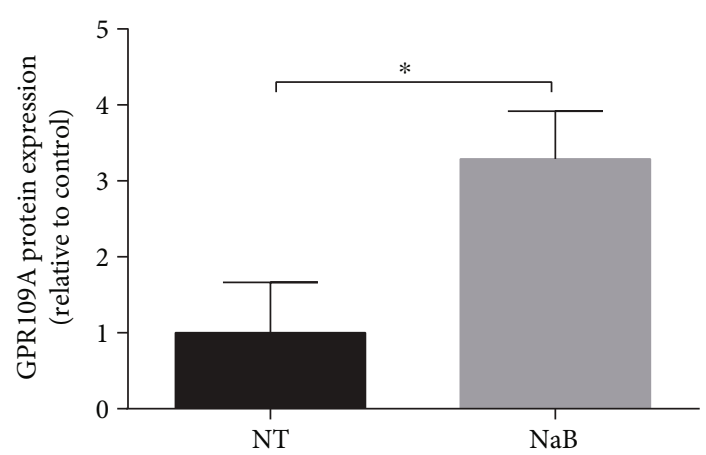

(e)

FIGURE 5: NaB suppresses APP expression and increases the BDNF/NEP level in a GPR109A-dependent manner in the protein level. The N2a cells were pretreated for 1 hour with $1 \mathrm{mM}$ PTX and then incubated for 24 hours with $2 \mathrm{mM} \mathrm{NaB}$. (a) Protein expression of APP, NEP, BDNF, and GPR109A in N2a cells was assessed by western blotting $(n=3)$; $\beta$-tubulin was used as an internal loading control. (b-e) Quantitative analysis of the expression of APP, BDNF, NEP, and GPR109A of no treatment (NT), NaB-treated (NaB), and PTX and NaB-treated (PTX $+\mathrm{NaB})\left(n=3\right.$, means $\pm \mathrm{SD}$, Student's $t$-test, ${ }^{*} P<0.05,{ }^{* *} P<0.01,{ }^{* * *} P<0.001$, and $\left.{ }^{* * * *} P<0.0001\right)$. 2 mM NaB reduced expression of APP and increased expression of BDNF and NEP. Simultaneously, NaB promoted the expression of the GPR109A.

BDNF, reduces the accumulation of ROS, and reverses the decrease of cell activity caused by $\mathrm{A} \beta$, by activating $\mathrm{G}$ protein, especially GPR109A, which may provide new ideas for the treatment of $\mathrm{AD}$.

\section{Data Availability}

"The data used to support the findings of this study are available from the corresponding author upon request." 


\section{Conflicts of Interest}

None of the authors or funding sources have conflict of interest.

\section{Authors' Contributions}

JX Sun and BY Yuan performed most of the experiments, analyzed the results, and wrote the manuscript. W Wang and YX Luan conceived and designed the study and analyzed the data. All authors have read and approved the final manuscript. JX Sun and BY Yuan contributed equally to this work.

\section{Acknowledgments}

The authors acknowledge the financial supported by the National Nature Science Foundation of China (Project No. 31872442) and the Graduate Innovation Fund of Jilin University (Project No. 201910183730).

\section{References}

[1] L. Aron and B. A. Yankner, "Neural synchronization in Alzheimer's disease," Nature, vol. 540, no. 7632, pp. 207-208, 2016.

[2] Z. Hui, Y. Zhijun, Y. Yushan et al., "The combination of acyclovir and dexamethasone protects against Alzheimer's disease-related cognitive impairments in mice," Psychopharmacology, vol. 27, 2020.

[3] A. Roher, D. Wolfe, M. Palutke, and D. KuKuruga, "Purification, ultrastructure, and chemical analysis of Alzheimer disease amyloid plaque core protein," Proceedings of the National Academy of Sciences of the United States of America, vol. 83, no. 8, pp. 2662-2666, 1986.

[4] R. Briggs, S. P. Kennelly, and D. O'Neill, "Drug treatments in Alzheimer's disease," Clinical Medicine, vol. 16, no. 3, pp. 247-253, 2016.

[5] A. B. Reiss, H. A. Arain, M. M. Stecker, N. M. Siegart, and L. J. Kasselman, "Amyloid toxicity in Alzheimer's disease," Reviews in the Neurosciences, vol. 29, no. 6, pp. 613-627, 2018.

[6] R. E. Tanzi and L. Bertram, "Twenty years of the Alzheimer's disease amyloid hypothesis: a genetic perspective," Cell, vol. 120, no. 4, pp. 545-555, 2005.

[7] T. Wisniewski and F. Goni, "Immunotherapeutic approaches for Alzheimer's disease," Neuron, vol. 85, no. 6, pp. 11621176, 2015.

[8] R. A. Hickman, A. Faustin, and T. Wisniewski, "Alzheimer disease and its growing epidemic: risk factors, biomarkers, and the urgent need for therapeutics," Neurologic Clinics, vol. 34, no. 4, pp. 941-953, 2016.

[9] R. J. Ferrante, J. K. Kubilus, J. Lee et al., "Histone deacetylase inhibition by sodium butyrate chemotherapy ameliorates the neurodegenerative phenotype in Huntington's disease mice," The Journal of Neuroscience, vol. 23, no. 28, pp. 9418-9427, 2003.

[10] Y. P. Silva, A. Bernardi, and R. L. Frozza, "The role of shortchain fatty acids from gut microbiota in gut-brain communication," Frontiers in Endocrinology, vol. 11, p. 25, 2020.

[11] S. Srivastav, S. Neupane, S. Bhurtel et al., "Probiotics mixture increases butyrate, and subsequently rescues the nigral dopa- minergic neurons from MPTP and rotenone-induced neurotoxicity," The Journal of Nutritional Biochemistry, vol. 69, pp. 73-86, 2019.

[12] R. M. Stilling, M. van de Wouw, G. Clarke, C. Stanton, T. G. Dinan, and J. F. Cryan, "The neuropharmacology of butyrate: the bread and butter of the microbiota-gut-brain axis?," Neurochemistry International, vol. 99, pp. 110-132, 2016.

[13] B. Sun, Y. Jia, S. Yang et al., "Sodium butyrate protects against high-fat diet-induced oxidative stress in rat liver by promoting expression of nuclear factor E2-related factor 2," British Journal of Nutrition, vol. 122, no. 4, pp. 400-410, 2019.

[14] M. Pohanka, "Oxidative stress in Alzheimer disease as a target for therapy," Bratislavské Lekárske Listy, vol. 119, no. 9, pp. 535-543, 2018.

[15] D. A. Butterfield and B. Halliwell, "Oxidative stress, dysfunctional glucose metabolism and Alzheimer disease," Nature Reviews. Neuroscience, vol. 20, no. 3, pp. 148-160, 2019.

[16] W. Fernando, I. J. Martins, M. Morici et al., "Sodium butyrate reduces brain amyloid- $\beta$ levels and improves cognitive memory performance in an Alzheimer's disease transgenic mouse model at an early disease stage," Journal of Alzheimer's Disease, vol. 74, no. 1, pp. 91-99, 2020.

[17] S. Amisten, M. Neville, R. Hawkes, S. J. Persaud, F. Karpe, and A. Salehi, "An atlas of G-protein coupled receptor expression and function in human subcutaneous adipose tissue," Pharmacology \& Therapeutics, vol. 146, pp. 61-93, 2015.

[18] D. Wanders, E. C. Graff, and R. L. Judd, "Effects of high fat diet on GPR109A and GPR81 gene expression," Biochemical and Biophysical Research Communications, vol. 425, no. 2, pp. 278-283, 2012.

[19] Y. Liang, C. Lin, Y. Zhang, Y. Deng, C. Liu, and Q. Yang, "Probiotic mixture of Lactobacillus and Bifidobacterium alleviates systemic adiposity and inflammation in non-alcoholic fatty liver disease rats through Gpr109a and the commensal metabolite butyrate," Inflammopharmacology, vol. 26, no. 4, pp. 1051-1055, 2018.

[20] W. Feng, Y. Wu, G. Chen et al., "Sodium butyrate attenuates diarrhea in weaned piglets and promotes tight junction protein expression in Colon in a GPR109A-dependent manner," Cellular Physiology and Biochemistry, vol. 47, no. 4, pp. 1617-1629, 2018.

[21] Y. Furusawa, Y. Obata, S. Fukuda et al., "Commensal microbe-derived butyrate induces the differentiation of colonic regulatory T cells," Nature, vol. 504, no. 7480, pp. 446-450, 2013.

[22] T. Yang, V. Rodriguez, W. L. Malphurs et al., "Butyrate regulates inflammatory cytokine expression without affecting oxidative respiration in primary astrocytes from spontaneously hypertensive rats," Physiological Reports, vol. 6, no. 14, article e13732, 2018.

[23] R. Patnala, T. V. Arumugam, N. Gupta, and S. T. Dheen, "HDAC inhibitor sodium butyrate-mediated epigenetic regulation enhances neuroprotective function of microglia during ischemic stroke," Molecular Neurobiology, vol. 54, no. 8, pp. 6391-6411, 2017.

[24] M. J. Park and F. Sohrabji, "The histone deacetylase inhibitor, sodium butyrate, exhibits neuroprotective effects for ischemic stroke in middle-aged female rats," Journal of Neuroinflammation, vol. 13, no. 1, p. 300, 2016.

[25] J. Jaworska, M. Ziemka-Nalecz, J. Sypecka, and T. Zalewska, "The potential neuroprotective role of a histone deacetylase 
inhibitor, sodium butyrate, after neonatal hypoxia-ischemia," Journal of Neuroinflammation, vol. 14, no. 1, p. 34, 2017.

[26] P. Wang, Y. Zhang, Y. Gong et al., "Sodium butyrate triggers a functional elongation of microglial process via Akt-small RhoGTPase activation and HDACs inhibition," Neurobiology of Disease, vol. 111, pp. 12-25, 2018.

[27] S. P. Fu, J. F. Wang, W. J. Xue et al., “Anti-inflammatory effects of BHBA in both in vivo and in vitro Parkinson's disease models are mediated by GPR109A-dependent mechanisms," Journal of Neuroinflammation, vol. 12, no. 1, p. 9, 2015.

[28] Y. Wu, Y. Gong, Y. Luan et al., "BHBA treatment improves cognitive function by targeting pleiotropic mechanisms in transgenic mouse model of Alzheimer's disease," The FASEB Journal, vol. 34, no. 1, pp. 1412-1429, 2020.

[29] X. Wang, X. Zhou, G. Li, Y. Zhang, Y. Wu, and W. Song, "Modifications and trafficking of APP in the pathogenesis of Alzheimer's disease," Frontiers in Molecular Neuroscience, vol. 10, p. 294, 2017.

[30] H. Zhao, S. Li, Z. Li et al., "Intranasal delivery of 9-cis retinoic acid reduces beta-amyloid deposition via inhibiting astrocytemediated inflammation," Aging, vol. 12, 2020.

[31] S. Wójtowicz, A. K. Strosznajder, M. Jeżyna, and J. B. Strosznajder, "The novel role of PPAR alpha in the brain: promising target in therapy of Alzheimer's disease and other neurodegenerative disorders," Neurochemical Research, vol. 13, 2020.

[32] C. Wei, J. Fan, X. Sun et al., "Acetyl-11-keto- $\beta$-boswellic acid ameliorates cognitive deficits and reduces amyloid- $\beta$ levels in APPswe/PS1dE9 mice through antioxidant and antiinflammatory pathways," Free Radical Biology \& Medicine, vol. 150, pp. 96-108, 2020.

[33] N. Wang, H. Wang, L. Li et al., " $\beta$-Asarone Inhibits Amyloid- $\beta$ by Promoting Autophagy in a Cell Model of Alzheimer's Disease," Frontiers in Pharmacology, vol. 10, p. 1529, 2020.

[34] S. Tiwari, V. Atluri, A. Kaushik, A. Yndart, and M. Nair, "Alzheimer's disease: pathogenesis, diagnostics, and therapeutics," International Journal of Nanomedicine, vol. 14, pp. 5541-5554, 2019.

[35] M. D. Tambini, K. A. Norris, and L. D'Adamio, "Opposite changes in APP processing and human A $\beta$ levels in rats carrying either a protective or a pathogenic APP mutation," Elife, vol. 9, 2020.

[36] W.-J. Song, E.-A. C. Song, M.-S. Jung et al., "Phosphorylation and inactivation of glycogen synthase kinase $3 \beta$ (GSK3 $\beta$ ) by dual-specificity tyrosine phosphorylation-regulated kinase $1 \mathrm{~A}$ (Dyrk1A)," Journal of Biological Chemistry, vol. 290, no. 4, pp. 2321-2333, 2015.

[37] T. Seki, M. Kanagawa, K. Kobayashi et al., "Galectin 3-binding protein suppresses amyloid- $\beta$ production by modulating $\beta$ cleavage of amyloid precursor protein," Journal of Biological Chemistry, vol. 295, no. 11, pp. 3678-3691, 2020.

[38] Z. Peng, Y. Luo, and Z. Y. Xiao, “Angiopoietin-1 accelerates Alzheimer's disease via FOXA2/PEN2/APP pathway in APP/PS1 mice," Life Sciences, vol. 246, p. 117430, 2020.

[39] D. Kumar, A. Sharma, and L. Sharma, "A comprehensive review of Alzheimer's association with related proteins: pathological role and therapeutic significance," Current Neuropharmacology, vol. 18, 2020.

[40] G. Esquerda-Canals, L. Montoliu-Gaya, J. Güell-Bosch, and S. Villegas, "Mouse models of Alzheimer's disease," Journal of Alzheimer's Disease, vol. 57, no. 4, pp. 1171-1183, 2017.
[41] J. Dorszewska, M. Prendecki, A. Oczkowska, M. Dezor, and W. Kozubski, "Molecular basis of familial and sporadic Alzheimer's disease," Current Alzheimer Research, vol. 13, no. 9, pp. 952-963, 2016.

[42] S. Alsunusi, T. A. Kumosani, C. G. Glabe, E. A. Huwait, and S. S. Moselhy, "In vitro study of the mechanism of intraneuronal $\beta$-amyloid aggregation in Alzheimer's disease," Archives of Physiology and Biochemistry, pp. 1-8, 2020.

[43] W. Ali, M. Ikram, H. Y. Park et al., "Oral administration of alpha linoleic acid rescues $\mathrm{A} \beta$-induced Glia-mediated neuroinflammation and cognitive dysfunction in C57BL/6N mice,", Cells, vol. 9, no. 3, p. 667, 2020.

[44] C. R. Campos, A. M. Kemble, J. Niewoehner, P. O. Freskgård, and E. Urich, "Brain shuttle neprilysin reduces central Amyloid- $\beta$ levels," PLoS One, vol. 15, no. 3, article e0229850, 2020.

[45] T. Grimmer, O. Goldhardt, I. Yakushev et al., "Associations of neprilysin activity in CSF with biomarkers for Alzheimer's disease," Neurodegenerative Diseases, vol. 19, no. 1, pp. 43-50, 2019.

[46] C. Klein, G. Roussel, S. Brun et al., "5-HIAA induces neprilysin to ameliorate pathophysiology and symptoms in a mouse model for Alzheimer's disease," Acta Neuropathologica Communications, vol. 6, no. 1, p. 136, 2018.

[47] R. J. Baranello, K. L. Bharani, V. Padmaraju et al., “Amyloidbeta protein clearance and degradation (ABCD) pathways and their role in Alzheimer's disease," Current Alzheimer Research, vol. 12, no. 1, pp. 32-46, 2015.

[48] K. Hornung, S. Zampar, N. Engel et al., "N-terminal truncated A $\beta 4-42$ is a substrate for neprilysin degradation in vitro and in vivo," Journal of Alzheimer's Disease, vol. 67, no. 3, pp. 849-858, 2019.

[49] N. Yamamoto, R. Ishikuro, M. Tanida, K. Suzuki, Y. IkedaMatsuo, and K. Sobue, "Insulin-signaling pathway regulates the degradation of amyloid $\beta$-protein via astrocytes," Neuroscience, vol. 385, pp. 227-236, 2018.

[50] L. Wei, S. Lv, Q. Huang et al., "Pratensein attenuates A $\beta$ induced cognitive deficits in rats: enhancement of synaptic plasticity and cholinergic function," Fitoterapia, vol. 101, pp. 208-217, 2015.

[51] M. L. Giuffrida, A. Copani, and E. Rizzarelli, "A promising connection between BDNF and Alzheimer's disease," Aging, vol. 10, no. 8, pp. 1791-1792, 2018.

[52] J. H. Song, J. T. Yu, and L. Tan, "Brain-derived neurotrophic factor in Alzheimer's disease: risk, mechanisms, and therapy," Molecular Neurobiology, vol. 52, no. 3, pp. 1477-1493, 2015.

[53] H. Tanila, "The role of BDNF in Alzheimer's disease," Neurobiology of Disease, vol. 97, part B, pp. 114-118, 2017.

[54] S. H. Choi, E. Bylykbashi, Z. K. Chatila et al., "Combined adult neurogenesis and BDNF mimic exercise effects on cognition in an Alzheimer's mouse model," Science, vol. 361, no. 6406, p. eaan8821, 2018.

[55] J. Pang, J. Hou, Z. Zhou et al., "Safflower yellow improves synaptic plasticity in APP/PS1 mice by regulating microglia activation phenotypes and BDNF/TrkB/ERK signaling pathway," NeuroMolecular Medicine, vol. 11, article 8591, 2020.

[56] K. W. Chang, H. F. Zong, K. G. Ma et al., "Activation of $\alpha 7$ nicotinic acetylcholine receptor alleviates $\mathrm{A} \beta_{1-42}$-induced neurotoxicity via downregulation of p38 and JNK MAPK signaling pathways," Neurochemistry International, vol. 120, pp. 238250,2018 
[57] M. Kowalska, K. Wize, M. Prendecki, M. Lianeri, W. Kozubski, and J. Dorszewska, "Genetic variants and oxidative stress in Alzheimer's disease," Current Alzheimer Research, vol. 17, 2020.

[58] B. Li, J. Liu, G. Gu, X. Han, Q. Zhang, and W. Zhang, "Impact of neural stem cell-derived extracellular vesicles on mitochondrial dysfunction, sirtuin 1 level and synaptic deficits in Alzheimer's disease," Journal of Neurochemistry, no. article e15001, 2020.

[59] W. Ahmad, B. Ijaz, K. Shabbiri, F. Ahmed, and S. Rehman, "Oxidative toxicity in diabetes and Alzheimer's disease: mechanisms behind ROS/RNS generation," Journal of Biomedical Science, vol. 24, no. 1, article 379, p. 76, 2017. 